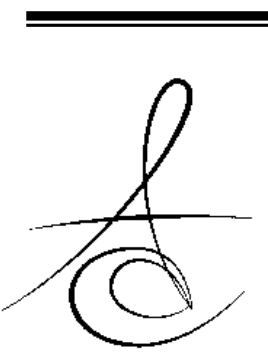

\title{
FARKLI NİKEL-TİTANYUM DÖNER ALET SİSTEMLERİNİN FARKLI KİNEMATİKLERDE KULLANIMININ ENDODONTİK TEDAVİ GÖRMÜŞ KÖKLERİN KIRILMA DİRENCİNE OLAN ETKİSİNİN İNCELENMESİ
}

\section{EVALUATION OF THE EFFECT OF DIFFERENT NICKEL-TITANIUM SYSTEMS BY USING DIFFERENT KINEMATICS ON THE FRACTURE RESISTANCE OF ENDODONTICALLY TREATED ROOTS}

\author{
Dr. Öğr. Üyesi Ahmet Demirhan UYGUN*
}

Dr. Öğr. Üyesi Halit ALADAĞ**

Makale Kodu/Article code: 4392

Makale Gönderilme tarihi: 17.05 .2020

Kabul Tarihi: 06.10.2020

DOI : $10.17567 /$ ataunidfd. 806406
A.Demirhan Uygun: ORCID ID: 0001-0001-5704-183X

Halit Aladağ ORCID ID: 0000-0001-6794-3845

\section{ÖZ}

Amaç. Çalışmamızın amacı ProTaper Universal (PTU), ProTaper Gold (PTG), Twisted File Adaptive (TFA) ve WaveOne (WO) NiTi Döner Alet sistemlerini farklı kinematiklerde kullanarak yapılan kök kanal şekillendirilmesinin dişlerin kırılma dirençlerine olan etkisini araştırmaktır.

Gereç ve Yöntem. Tek köklü ve tek kanallı 160 adet alt kesici dişler seçildi. Dişler mine-sement birleşim yerinden ayrıldıktan sonra örnekler 8 gruba bölündü $(n=20)$. Grup 1 hariç diğer gruplarda $10 \mathrm{~K}$-tipi eğe kök kanallarında ilerletildi ve bu boydan 1 mm çıkartılarak çalışma uzunluğu belirlendi. 15 K-tipi eğe ile kayma yolu oluşturuldu. Kontrol grubunda köklere hiçbir şekillendirme işlemi yapılmadı. WO eğeleri sadece resiprokasyon hareketinde kullanıldı. Diğer eğeler ise hem üretici talimatlarındaki hareketle hem de resiprokasyon hareketiyle kullanıldılar.

Örneklere periodontal ligamentleri taklit etmesi amacıyla elastomerik ölçü maddesi kullanıldı. Daha sonra Universal test cihazında $1 \mathrm{~mm}$ / dakika hızla örneklere kuvvet uygulandı. Örneklerde kırılmaya neden olan maksimum kuvvet değerleri ( F-Max) belirlendi ve sonuçlar tek yönlü varyans analizi (ANOVA) ve post-hoc LSD testleri kullanılarak istatistiksel değerlendirilmeye tabi tutuldu. $(P<0.05)$

Bulgular. Kontrol grubu en yüksek kırılma direncine sahipti ve PTU, PTU resiprokasyon ve PTG ve PTG resiprokasyon sistemleriyle arasında istatistiksel açıdan anlamlı fark vardı. $(P<0.05)$. TFA, TFA resiprokasyon ve WO grupları ile kontrol grubu arasında köklerin kırılmaya karşı dirençleri açısından istatistiksel olarak anlamlı fark yoktu $(P>0.05)$.

Sonuç. Çalışmamızda rotasyon veya resiprokasyon hareketiyle kök kanalları genişletilmesinin dişlerin kırıma direncinde bir fark yaratmadığı görülmüştür fakat PTU ve PTG gruplarının dişlerin kırılma dirençlerini azalttığı sonucuna varılmıştır.

Anahtar Kelimeler: ProTaper, Adaptive hareket, Rotasyon, Resiprokasyon

\section{ABSTRACT}

Aim. The aim of our study is to investigate the effect of the preparation on the fracture resistance of teeth by using ProTaper Universal (PTU), ProTaper Gold (PTG), Twisted File Adaptive (TFA) and WaveOne (WO) NiTi rotary instrument systems in different kinematics.

Material and methods. 160 mandibular incisor teeth with single root and single canal were chosen. After the teeth were separated from the cementoenamel junction, the roots were divided into eight groups $(n=20)$. All groups except for group 1 , the working length of the root canals were determined by inserting a size $10 \mathrm{~K}$-type file into the root canal terminus and subtracting $1 \mathrm{~mm}$ from this measurement. A glide path was done via a size $15 \mathrm{~K}$-type file. In the control group, the root canals were not prepared. WO files were used only in the reciprocating motion. Other files were used both with the movement in the manufacturer's instructions and with the reciprocating movement. The periodontal ligament was simulated by using elastomeric impression material. Vertical loading was carried out with a universal testing machine at $1 \mathrm{~mm} / \mathrm{min}$ crosshead speed. The maximum force at fracture (F-max) was recorded for each root and the data were analyzed statistically by one way analysis of variance (ANOVA) and post-hoc LSD tests $(P<0.05)$.

Results. The control group presented the highest fracture resistance and differed significantly from PTU, PTU reciprocation, PTG and PTG reciprocation groups $(P<0.05)$. There were no significant differences in the fracture resistance between control group, and TFA, TFA reciprocation and WO groups $(P>0.05)$.

Conclusion. In our study, it was observed that the root canal preparation did not make a difference in the fracture resistance of the teeth by rotation or reciprocation movement, but it was concluded that PTU and PTG groups reduced the fracture resistance of the teeth.

Key Words: ProTaper, Adaptive motion, Rotation, Reciprocation

*Afyonkarahisar Sağlık Bilimleri Üniversitesi, Diş Hekimliği Fakültesi, Endodonti A.D. Afyonkarahisar.

${ }^{* *}$ Atatürk Üniversitesi, Diş Hekimliği Fakültesi, Endodonti A.D. Erzurum.

Kaynakça Bilgisi: Uygun AD, Aladağ H. Farklı Nikel-Titanyum Döner Alet Sistemlerinin Farklı Kinematiklerde Kullanımının Endodontik Tedavi Görmüş Köklerin Kırılma Direncine Olan Etkisinin İncelenmesi. Atatürk Üniv Diş Hek Fak Derg 2021; 31: 221-7.

Citation Information: Uygun $A D$, Aladag $\mathrm{H}$. Evaluation of the effect of different nickel-titanium systems by using different kinematics on the fracture resistance of endodontically treated roots. J Dent Fac Atatürk Uni 2021; 31: 221-7. 


\section{GİRİŞ}

Vertikal kök kırığı nadir gerçekleşen bir durum olmasına rağmen genellikle diş kaybına neden olan büyük bir problemdir. Kanal dolum işlemleri ve post uygulamaları, final kanal şekli, kanal genişletme derecesi ve kök yüzeyindeki düzensizlik ve defektler de vertikal kök kırığına sebep olur. ${ }^{1-5}$ Nikel-titanyum (NiTi) döner aletler ile yapılan kök kanal genişletme prosedürlerinin de dişlerin vertikal kök direncini düşürdüğü daha önceki çalışmalarla gösterilmiştir. ${ }^{6,7}$

Son yıllarda döner NiTi döner aletlerdeki teknolojik gelişmeler, yeni tasarım konseptlerine ve daha kolay, daha hızlı ve daha iyi kök kanal tedavilerine yol açtı. Çok tercih edilen ve uzun bir süredir kullanılmakta olan ProTaper Universal (PTU, Dentsply Maillefer, Ballaigues, İsviçre) aktif kesme hareketine ve koronale doğru daha çok dentin kaldırmasını sağlayan dışbükey üçgen kesitsel tasarıma ve değişken konikliğe sahip aletlerdir. ${ }^{8,9}$ Bununla birlikte PTU sisteminin günümüzde kullanılmakta olan diğer NiTi sistemlerine oranla daha çok dentin hasarına sebep olduğu bildirilmiştir. ${ }^{10}$ ProTaper Gold (PTG, Dentsply Tulsa Dental Specialities, Tulsa, OK, ABD) ise PTU sistemi ile aynı geometrik tasarıma sahiptir ancak bu aletler ısıl işleme tabi tutularak artmış esneklik ve direnç kazanmıştır. ${ }^{11,12}$ Yapılan çalışmalarda PTG sisteminin PTU sistemine kıyasla dentinde daha az mikroçatlağa neden olduğu görülmüştür. ${ }^{13,14}$

Teknolojik gelişmeler sadece NiTi döner aletlerin fiziksel özellikleri ile sınırlı kalmayıp aynı zamanda bu aletlerin kullanım kinematiklerini de etkiledi. İlk olarak Yared ${ }^{15}$ PTU sisteminin aletlerini sıralı bir şekilde kullanmayıp sadece F2 eğesi ile resiprokasyon hareketinde kök kanal tedavisini tamamlamıştır ve tek bir eğe ile kök kanal şekillendirilmesi konseptini ileri sürmüştür. Resiprokal hareket şekillendirme işlemi sırasında saat yönünde (SY) ve saat yönünün tersine (SYT) geniş bir kesme açısı ve aksi yönde daha dar bir açıyla eğenin dönüş yönünün sürekli değişmesiyle meydana gelir. Bu en uygun seçilen açılar aynı zamanda 'vidalanma' etkisi ve eğe kırılma riskinin azaltılmasını sağlar. Daha sonra buna istinaden resiprokal hareket ile kullanılan eğeler üretilmeye başlanmıştır. Bu resiprokasyon hareketinin konvansiyonel rotasyon hareketine kıyasla dentin için daha güvenli olduğu iddia edilmektedir. ${ }^{16}$ WaveOne (WO, Dentsply Maillefer, Ballaigues, İsviçre) resiprokal hareket ile çalışan ve sadece tek bir eğe ile kök kanal genişletmesinin tamamlanabildiği bir sistemdir. ${ }^{17}$ Twisted File Adaptive (TFA, Axis/ SybronEndo, Orange, CA, ABD) sistemi farklı bir hareket prensibi olan adaptive hareket ile kullanılan diğer bir NiTi döner alet sistemidir. ${ }^{18}$ Adaptive hareket siste- min kendi endomotoru olan Elements motor (Axis/ SybronEndo, Orange, CA, ABD) ile yapılabilmektedir. Bu hareket prensibinin farkı minimal veya hiçbir kuvvet yokken eğe rotasyon hareketi yaparken, dentine sıkıştığında veya bir baskı ile karşılaştığında resiprokasyon hareketi yapmasıdır. ${ }^{19,} 20$ PTU ve WO sistemlerine göre daha az dentin çatlağına neden olduğu rapor edilmiştir. ${ }^{21}$

Farklı üretim teknolojilerine ve farklı hareket kinematiklerine sahip bu NiTi döner aletlerle şekillendirilmiş köklerin vertikal kırılma direnciyle ilgili literatürde sınırlı bilgi mevcuttur. Bu çalışmanın amacı, PTU, PTG, WO ve TFA döner aletleri ile kök kanal şekillendirmesi yapılan köklerin kırılma dirençlerini hem üretici talimatlarındaki harekette hem de resiprokal harekette kıyaslamaktır.

\section{GEREÇ VE YÖNTEM \\ Örneklerin hazırlanması}

Çalışmaya başlamadan önce etik kurul onayı alındı. Çalışmamıza tek köklü protetik veya periodontal sebeplerden ötürü çekilmiş, çürüksüz, sağlam, kök ucu oluşumu tamamlanmış, benzer boyutlarda tek köklü ve tek kanallı 160 adet alt çene kesici dişleri dahil edildi. Diş taşları ve yumuşak doku artıkları periodontal küret ile temizlendi. Dişler çalışma başlayıncaya kadar distile suda oda sıcaklığında bekletildi. Her üç günde bir su değiş̧irilerek dişlerin taze olarak saklanması amaçlandı. Çalışmamızda kullanılacak dişlerden bukkolingual ve meziodistal yönde radyografi alınarak kalsifikasyon gözlenmeyen dişler çalışmaya dahil edildi. Ayrıca dişler $\times 20$ büyütmede stereomikroskop (Novex, Arnham, Hollanda) altında incelenerek çatlak ve kırığa sahip olan dişler çalışmamıza alınmadı.

Seçilen dişlerin kuron ve kökleri su soğutması altında elmas separe ile mine-sement birleşiminden kesilerek, dişler $13 \mathrm{~mm}$ uzunlukta olacak şekilde standardize edildi. Elektronik kumpas yardımıyla dişlerin mesiodistal ve bukkolingual çapları ölçülerek belli standartlardaki dişler çalışmamıza dahil edildi. Dişler varyans analizine göre dijital hassas terazi kullanılarak ağırlıklarına göre her grupta 20 diş olacak şekilde 8 gruba ayrıldı. Gruplar arasında ağırıklar bakımından istatistiksel olarak anlamlı bir fark yoktu ( $p>0.05)$.

\section{Örneklerin kök kanal genişletmesi}

Grup 1 hariç diğer gruplarda \#10 K-tipi eğe kök kanallarında ilerletildi ve bu boydan $1 \mathrm{~mm}$ çıkartılarak çalışma uzunluğu belirlendi. \#15 K-tipi eğeyle bütün gruplarda rehber yol oluşturuldu. 
Grup 1: Kök kanal genişletilmesi yapılmadı.

Grup 2: Bu grupta kök kanalları PTU aletlerle devamlı rotasyon hareketinde (SY $360^{\circ}$ ) şekillendirildi. Aletlerin S1, SX, S2, F1ve F2 idi. SX çalışma boyunun yarısına kadar kullanıldı ve şekillendirme eğeleri SX, S1veS2 fırçalama hareketi ile kullanıldı. Bitirme eğeleri ise çalışma uzunluğuna ulaşana kadar yumuşak ileri geri hareketle kullanıldı.

Grup 3: Tüm kök kanalları PTU F2 eğesi ile resiprokasyon hareketinde (SY $170^{\circ}-\mathrm{SYT} 50^{\circ}$ ) şekillendirildi. Şekillendirme esnasında yumuşak gagalama hareketi ve hafif apikal basınç uygulandı. Daha çok baskı gerektiren bir dirençle karşılaşıldığında alet çıkarıldı ve yivleri temizlendi. Bu işlem apikale ulaşılıncaya kadar tekrar edildi.

Grup 4: Bu grupta kök kanalları PTG eğelerle devamlı rotasyon hareketinde (SY $360^{\circ}$ ) şekillendirildi. Aletler grup 2' ye benzer şekilde kullanıldı.

Grup 5: Tüm kök kanalları PTG F2 eğesi ile resiprokasyon hareketinde (SY $170^{\circ}$-SYT $50^{\circ}$ ) şekillendirildi. Şekillendirme grup 3'tekine benzer şekilde yapıldı.

Grup 6: Bu grupta kök kanalları TFA eğelerle adaptive hareket ile (rotasyon hareketinde SY $600^{\circ}$-SYT $0^{\circ}$ ve resiprokasyon hareketinde SY $375^{\circ}$-SYT $50^{\circ}$ ) şekillendirildi. Aletler sırasıyla SM1, SM2 ve ML1 idi. TFA ML1 çalışma uzunluğuna ulaşana kadar yumuşak ileri geri hareketle kullanıldı.

Grup 7: Tüm kök kanalları TFA ML1 eğesi ile resiprokasyon hareketinde (SY $170^{\circ}-\mathrm{SYT} 50^{\circ}$ ) şekillendirildi.

Grup 8: Tüm kök kanalları WO Primary eğesi ile resiprokasyon hareketinde (SYT $170^{\circ}-\mathrm{SY} 50^{\circ}$ ) şekillendirildi.

\section{Kırma deneyinin yapılışı}

Kanal şekillendirilmesi yapılan dişler kırma deneyi için 20 mm çapında ve 20 mm yüksekliğinde hazırlanmış plastik silindir kalıplar içerisindeki akrilik rezine (IMICRYL, Konya, Türkiye) gömüldü. Akrilik rezine dişleri gömmeden önce çevre dokuları taklit etmek amacıyla köklerin apikal 5 mm'lik kısımları erimiş muma daldırıldı. Daha sonra dişler 8 mm'si dışarıda kalacak şekilde akrilik rezine gömüldü. Polimerizasyon başladığında örnekler çıkarılarak kök yüzeylerindeki mum küret yardımıyla temizlendi ve bu yüzeyler ince bir tabaka halinde enjeksiyon tipi vinylpolsiloxane ölçü maddesi (Elite HD, Zhermack, İtalya) ile kaplandı ve tekrar akrilik rezin içerisine gömülerek polimerizasyon için bekletildi. Kırma deneyi için dişler universal test cihazının (UTC) (Instron Corp, ABD) alt sabitleyici parçasına yerleştirildi (Şekil 1). Örneklere kuvvet 3,6 mm çapında paslanmaz çelik küreyle uygulandı. UTC kuvvet uygulayacak paslanmaz çelik ucu, dişin uzun aksına paralel olacak şekilde ayarlandı ve test cihazı $1 \mathrm{~mm} / \mathrm{dk}$ hızında kuvvet uygulayacak şekilde dişe yönlendirildi. Dişlerde kırılma gerçekleştiğinde test makinası durdurularak ekrandaki değerler Newton (N) cinsinden kaydedildi.

\section{İstatistiksel Analiz}

Kırma deneyi verilerine göre gruplar arasındaki farklılıklar tek yönlü varyans analizi (ANOVA) ve posthoc LSD (en az anlamlı farklılık) çoklu karşılaştırma testi ile istatistiksel olarak analiz edildi $(p<0.05)$.

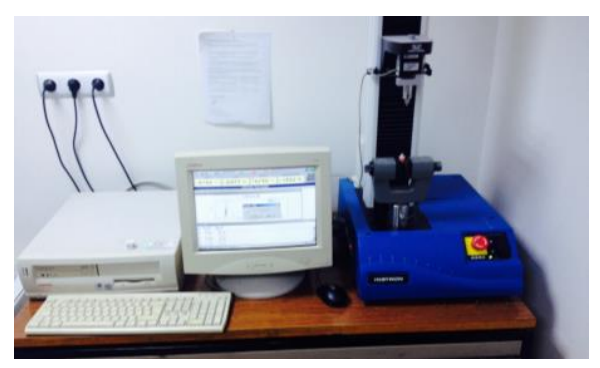

Şekil 1. Çalışmamızda Kullanılan Universal Test Cihazı

\section{BULGULAR}

Çalışmamızda farklı NiTi döner alet sistemlerinin dişlerin kırılma direncine olan etkisinin incelendiği çalışmamızda kırılma değerleri arasında farklılıkların bulunduğu ve bu farklılıkların istatistiksel açıdan anlamlı olduğu görüldü $(p<0.05)$. Grupların ortalama kırılma değerleri $(\mathrm{N})$ ve standart sapmaları Tablo $1^{\prime}$ de gösterilmiştir.

Tablo 1. Ortalama Kırılma Değerleri Ve Standart Sapmaları(SS)

\begin{tabular}{lll}
\hline Gruplar & N & Ortalama \pm SS \\
\hline Kontrol (genişletme yapılmayan) & 20 & $666,067 \pm 136,6926$ \\
PTU & 20 & $568,089 \pm 118,5440$ \\
PTU resiprokasyon & 20 & $543,772 \pm 107,9744$ \\
PTG & 20 & $549,817 \pm 161,1419$ \\
PTG resiprokasyon & 20 & $528,689 \pm 98,8386$ \\
TFA & 20 & $604,294 \pm 103,7203$ \\
TFA resiprokasyon & 20 & $621,333 \pm 97,4177$ \\
WO & 20 & $605,828 \pm 102,3470$ \\
\hline
\end{tabular}

Grup 1 (kontrol grubu)' deki örneklerin kırımaya karşı dirençleri tüm deney grupları arasında en yüksek değerleri gösterdi. Grup 6 (TFA rotasyon), Grup 7 (TFA resiprokasyon) ve Grup 8 (WO) hariç diğer gruplara göre istatistiksel olarak anlamlı yüksek kırılma direncine sahipti. Şekillendirme yapılan kök grupları kendi aralarında karşılaştırıldığında, bir tek TFA resiprokasyon grubu PTG resiprokasyon grubuna 
göre anlamlı derecede yüksek kırılma direncine sahipti $(p<0.05)$. Çalışmamızda resiprokasyon ve rotasyon grupları arasında bir fark bulunmamıştır.

\section{TARTIŞMA}

Literatürde kök kanal tedavisi görmüş dişlerde vital dişlere nazaran daha çok vertikal kök kırı̆ı̆ oluştuğu rapor edilmiştir. ${ }^{22-24}$ Endodontik tedavi görmüş bir dişin dayanıklıı̆ı direkt olarak kök kanalının şekillendirmesinde kullanılan yöntem ve kalan diş yapısı ile ilişkili olduğu gösterilmiştir ve genel olarak dentin dokusu kaybının kök direncini düşürdüğü söylenebilir. 24, $25 \mathrm{Bu}$ nedenle bu çalışmanın amacı farklı NiTi döner alet sistemlerinin vertikal kök kırığı riskini nasıl etkilediğini araştırmaktır.

Kök kanal tedavisinde kullanılan döner aletlerle yapılan çalışmalarda karşılaşılan en büyük sorun; çekilmiş dişlerin yüksek standart sapmalara neden olması ve mekanik özellikler açısından farklılıklar göstermesidir. Bu farklılıklar hastanın yaşı, diş çekilmeden önceki pulpanın durumu, nem oranı ve dentinin kompozisyonuna bağlı olarak ortaya çıkmakta ve standart sapmanın çok geniş aralıkta olmasına sebep olmaktadır. Ancak dişlerin heterojen bir yapıya sahip olması ve tüm dişlerde böyle bu yapının varlığı; farklılıkların kabul edilebilir olmasını sağlamaktadır. 26, 27

Çalışmamızda anatomik ve biyolojik varyasyonların önüne geçebilmek için 45 yaş üstü bireylerde periodontal veya protetik amaçla çekilen, kök kanal şekillendirmesi yapılmadan bırakılan sahalardan mümkün olduğunca bağımsız olabilmek için alt kesici dişleri kullandık. Alt keser dişler oval yapısı itibari ile vertikal kök kırığına daha çok maruz kalır. ${ }^{1}$ Bu yüzden çalışmamızda diğer dişlere oranla daha zayıf olan alt kesici dişler seçildi.

Ertaş ve ark. ${ }^{28}$ dişlerin kırılma direncini araştırdıkları çalışmasına göre dişlerin hacim ve ağırlıklarının, bukkolingual ve mesiodistal çaplardan daha etkili olduğunu göstermişlerdir. Bizim çalışmamızda da örneklerin boyutlarını standardize edebilmek için dijital kumpas ile bukkolingual ve mesiodistal çaplar ölçüldü ve belli ölçülerdeki dişler çalışmaya dahil edildi. Daha sonra ağırlıklarına göre gruplara dağıtıldı.

Endodontik tedavide kök kanallarının dezenfeksiyonunda farklı irrigasyon solüsyonları kullanılmaktadır, ancak bunlar dentinin kimyasal ve yapısal kompozisyonunu etkileyebilir. Smear tabakasının kaldırmasında dentini demineralize eden \%15-17'lik EDTA solüsyonlarının, organik dokuları çözebilen \%1-6 NaOCl ile birlikte kullanılması önerilmektedir. ${ }^{29-31}$ İrrigasyon solüsyonlarının köklerin kırılma direncine olan etkisinin incelendiği başka bir çalışmada uygulama süresinin artması ile kırılma direncinin azaldığı rapor edilmiştir. ${ }^{32}$ Bu bilgiler sonucunda çalışmamızda her alet değişiminde $2 \mathrm{ml} \% 2.5 \mathrm{NaOCl}$ ile irrigasyon yaptık. Final yıkama için $1 \mathrm{dk} .5 \mathrm{ml} \% 17$ EDTA ve ardından $1 \mathrm{dk}$. 5 $\mathrm{ml} \% 2.5 \mathrm{NaOCl}$ ile irrigasyon yapıldı. Son olarak diğer irrigasyon solüsyonlarının etkilerini nötralize etmek için $5 \mathrm{ml}$ distile su kullanıldı.

Literatürde kök kanal dolgu maddelerinin ve kök kanal patlarının vertikal kırıma direncine etkisini inceleyen birçok çalışma vardır. Kanalları genişletilmemiş dişlerin ve genişletilmiş ama doldurulmayan dişlerin karşılaştırıldığı bir çalışmada, kanalları genişletilmeyen dişlerin kırılma direncinin istatistiksel olarak anlamlı şekilde yüksek çıktığını rapor etmişlerdir. ${ }^{33}$

Karapınar ve ark. ${ }^{34}$ çalışmalarında kanalları genişletilip doldurulmamış köklerin kırılma dirençlerinin çok düşük olduğunu, kök kanallarının doldurulmasının dişlere direnç kazandırdığını bildirmiştir. Yapılan başka bir çalışmada ise kök kanalları doldurulmuş örneklerin hiçbir işlem yapılmamış örneklere göre kırılma direncinin daha yüksek olduğunu rapor etmişlerdir. Dentin ve kök kanal patları arasında daha iyi bir adezyon olması için smear tabakasının kaldırılması gerektiği, bu sayede dentin tübüllerine kök kanal patlarının nüfusunun artması ile kırılma direncini artıracağı bildirilmiştir. ${ }^{35}$

Dişlerin servikal bölgelerini farklı konisite açısına sahip aletlerle şekillendirdikten sonra farklı kök kanal dolgu materyalleri ile doldurup kırılma dirençlerininin incelendiği bir çalışmada, hiçbir dolum materyalinin örneklerin kırılma direncini artırmadığı belirtilmiştir. Topçuoğlu ve ark. ${ }^{36} 2012$ yılında kök kanallarının genişletmesinin belirgin bir biçimde dişin destek dokularını zayıflattığı ve kök kırılma direncinin kök kanalları genişletilmeyen gruba nazaran istatistiksel olarak anlamlı derecede azaldığını fakat kök kanallarının doldurulmasının kök kırılma direncini artırmadığını bildirmişlerdir. Ersoy ve Evcil. ${ }^{37} 2015$ yılında farklı kök kanal dolgu maddeleri ve kök kanal patlarının vertikal kök direncine olan etkisini inceledikleri çalışmasında, kök kanalları genişletilmemiş grubun en yüksek değere sahip olduğunu, sadece thermafil dolum tekniğinin ise lateral kondensasyon, System B ve tek kon tekniğine göre kırılma direncini artırdığını bildirmişlerdir. Literatürde kök kanal dolgu materyallerinin ve bunların uygulanması esnasında oluşan kuvvetlerin dişlerin kök direncine olan etkisini inceleyen çalışmalarda bir fikir birliğine varılamamaktadır. Biz de farklı NiTi döner alet sistemlerinin kırılma direncine olan etkisini inceledi- 
ğimiz çalışmamızda kök kanal dolum materyallerinin veya işlemlerinin kök direncine olumlu veya olumsuz etkilerini elemine edebilmek için herhangi bir dolum işlemi yapmadık.

Bergman ve ark. ${ }^{38}$ farklı kök kanal aletlerinin şekillendirme etkinliklerini inceledikleri çalışmada aletlerin apikal boyutlarının benzer olmasının önemini bildirmiştir. Çalışmamızda benzer boyutlardaki döner aletler tercih edildi, çünkü farklı boyutlardaki aletler kullanıldığı zaman daha büyük boyuta sahip döner aletin kullanıldığı örneklerdeki kalan dentin kalınlığının azalmasından dolayı kırılma direnci de azalacaktır. Bu yüzden çalışmamızda son şekillendirme için apikal çapı \#25 ve \%8 konisiteye sahip benzer boyutlara sahip aletler seçildi.

Tavanafar ve ark. ${ }^{39}$ NiTi K-tipi eğe, BioRace (BR, FKG Dentaire; La-Chaux-de-Fonds, İsviçre) ve WaveOne sistemleri ile şekillendirilen dişlerin kırılma direncini inceledikleri çalışmasında, bütün sistemlerin kontrol grubuna göre kırılma direncini düşürürken, WaveOne grubunun kırılma direncini, el aleti ve BioRace gruplarına göre daha az düşürdüğünü bildirmiştirler. Bütün gruplarda örnekler \#40 numaralı apikal boyuta sahip aletlerle şekillendirilirken, Waveone $\% 8$ konikliğinde, BioRace ise \%4 konikliğindeki alet ile şekillendirilmiştir. Araştırmacılar bu sonuçların aletlerin esnekliği ve tasarımlarından kaynaklanabileceğini bildirmişlerdir. PTU ve One Shape (MicroMega, Besançon, Fransa) döner aletlerinin köklerin kırılma direncine olan etkisinin incelendiği başka bir çalışmada, PTU ile genişletilen köklerin daha az dirençli olduğu görülmüştür. ${ }^{40}$

Kök kanallarının şekillendirilmesi süresince kalan dentin miktarının azalması ile dişlerin kırılma dirençlerinin azalması kaçınılmazdır, ancak döner aletler ile kök kanalları şekillendirilirken kırılma direncini etkileyen tek faktör kalan dentin miktarı değildir. Araştırmacılar NiTi döner aletlerin kesit ve eksen özelliklerine ve esnekliklerine bağlı olarak, dentin duvarıyla temas ettikleri bölgelerde oluşturdukları streslerle el aletlerine oranla, dentinde çatlak hattı, parsiyel veya vertikal kırık gibi dentin çatlaklarının oluşma riskinin arttığını ve bu çatlakların, kanal doldurma ve çiğneme kuvvetlerinin etkisiyle vertikal kök kırı̆̆ına dönüşme ihtimalinin yüksek olduğunu belirtmişlerdir. ${ }^{9}$, ${ }^{41-43}$ Literatürde bizim çalışmamızda kullandığımız eğeleri birbirleriyle dişlerin kırıma dayanımına olan etkisi bakımından kıyaslayan bir araştırma bulunmamaktadır, ancak bu eğelerin dentin çatlağı oluşumuna etkisini inceleyen birçok çalışma vardır.
Karataş ve ark. ${ }^{21}$ PTU, ProTaper Next, TFA ve WO sistemlerini karşılaştırdıkları çalışmanın sonucunda koronal ve orta kesitler arasında fark bulamazken, apikal kesitlerde TFA ve ProTaper Next gruplarının daha az çatlak oluşumuna neden olduğunu bildirmişlerdir. Başka bir çalışmada K-tipi eğeler, ProTaper Universal el aletleri, PTU döner aleti ve WO kıyaslanmıştır. Kontrol ve K-tipi eğelerde çatlak bulunmazken en çok çatlak PTU döner aletinde bulunmuştur. ${ }^{44}$ Bizim çalışmamızla benzer olarak PTU aletinin hem rotasyon hem de resiprokasyon hareketinde kullanıldığı bir çalışmada, resiprokal hareketle çalışan WO ve PTU resiprokasyon grupları arasında istatistiksel olarak anlamlı fark olmazken, PTU rotasyon grubunun daha çok çatlağa neden olduğunu bildirmişlerdir. ${ }^{45}$

Nasr ve Kader ${ }^{43}$ tarafından rotasyon ve resiprokal hareketlerin kıyaslandığı başka bir çalışmada, PTU F2 rotasyon veya resiprokasyon hareketinde kullanıldığında fark yokken WO grubunda istatistiksel olarak daha az çatlak oluştuğunu bildirmişlerdir. Bu araştırmacılar PTU rotasyon grubunda diğer çalışmalardan farklı olarak rotasyon hareketinde sadece PTU F2 eğesini kullanmışlardır. Aynı çalışmada PTU ve WO sistemlerinin köklerin kırılma direncine olan etkisinide karşılaştıran araştırmacılar, WO grubunun kırılma direncini, PTU rotasyon ve resiprokasyon gruplarına göre daha yüksek bulmuşlardır. Araştırmacılar hareket kinematiğinden ziyade bu aletlerin metalürjisi ve tasarımının dentin hasarı oluşumunda daha etkili olduğunu ileri sürmektedirler.

Ayrıca bu çalışmanın sonuçlarına göre dentin çatlağı çalışmaları ve kırılma direnci çalışmaları arasında direk bir ilişki olduğu da ortaya konulmaktadır. Bizim çalışmamızda bu çalışma ile uyumlu olarak, aynı eğe sistemini seri halinde rotasyon veya son eğeyi resiprokasyon modunda kullandığımızda kırılma direnci açısından bir fark yaratmamıştır. En yüksek değerler kontrol grubunda olmak üzere, TFA grupları ve WO grubu ile kırılma direnci açısından istatistiksel olarak anlamlı bir fark yokken, PTU ve PTG grupları kırılma direncini istatistiksel olarak anlamlı olarak azaltmaktadır.

\section{SONUÇ}

Çalışmamızda son eğenin resiprokasyonda veya sistemin tüm eğelerinin sıra ile rotasyonda kullanılmasının istatistiksel olarak bir fark yaratmadığı ve hareket kinematiklerinden ziyade eğelerin metalürjisi veya geometrik tasarımının dişlerin kırılma direncini etkilediği görülmüştür. 
Cıkar çatısması: Bu makale yazarlarından hiçbirinin makalede bahsi geçen konu veya malzemeyle ilgili herhangi bir iliskkisi, bağlantısı veya parasal çıar durumu söz konusu değildir. Bu çalışma daha önce herhangi bir bilimsel etkinlikte tebliğ edilmemiştir. Finansal destek bulunmamaktadır.

\section{KAYNAKLAR}

1. Sathorn C, Palamara JE, Palamara D, Messer HH. Effect of root canal size and external root surface morphology on fracture susceptibility and pattern: a finite element analysis. J Endod 2005;31:288-92.

2. Versluis $A$, Messer $H$, Pintado $M$. Changes in compaction stress distributions in roots resulting from canal preparation. Int Endod J 2006, 39: 931-9.

3. Wilcox LR, Roskelley C, Sutton T. The relationship of root canal enlargement to finger-spreader induced vertical root fracture. J Endod 1997;23: 533-4.

4. Dulaimi SF, Wali Al-Hashimi M. A comparison of spreader penetration depth and load required during lateral condensation in teeth prepared using various root canal preparation techniques. Int Endod J 2005, 38: 510-5.

5. Tamse A, Fuss Z, Lustig J Kaplavi J. An evaluation of endodontically treated vertically fractured teeth. J Endod 1999, 25: 506-8.

6. Capar ID, Altunsoy M, Arslan $H$, Ertas $H$, Aydinbelge HA. Fracture strength of roots instrumented with self-adjusting file and the ProTaper rotary systems. J Endod 2014;40: 551-4.

7. Sathorn C, Palamara JE, Messer HH. A comparison of the effects of two canal preparation techniques on root fracture susceptibility and fracture pattern. J Endod 2005; 31: 283-7.

8. Bergmans $L$, Van Cleynenbreugel J Beullens $M$, Wevers M, Van Meerbeek B, Lambrechts P. Abstract. Int Endod J 2002; 35: 820-8.

9. Bier CAS, Shemesh $H$, Tanomaru-Filho M, Wesselink PR, Wu M-K. The ability of different nickel-titanium rotary instruments to induce dentinal damage during canal preparation. J Endod 2009; 35:236-8.

10. Aksoy Ç, Keriş EY, Yaman SD, Ocak M, Geneci F, Çelik $\mathrm{HH}$. Evaluation of XP-endo shaper, reciproc blue, and protaper universal niti systems on dentinal microcrack formation using microcomputed tomography. J Endod 2019; 45:338-42.

11. Elnaghy A, Elsaka S. Mechanical properties of ProTaper Gold nickel-titanium rotary instruments. Int Endod J 2016; 49: 1073-8.

12. Uygun A, Kol E,Topcu M,Seckin F, Ersoy I, Tanriver M. Variations in cyclic fatigue resistance among ProTaper Gold, ProTaper Next and ProTaper Universal instruments at different levels. Int Endod ] 2016; 49: 494-9.
13. Karataş E, Gündüz H, Kırıcı D, Arslan H. Incidence of dentinal cracks after root canal preparation with ProTaper Gold, Profile Vortex, F360, Reciproc and ProTaper Universal instruments. Int Endod J 2016; 49: 905-10.

14. Bayram HM, Bayram E, Ocak M, Uygun AD, Celik $\mathrm{HH}$. Effect of ProTaper Gold, Self-Adjusting File, and XP-endo Shaper instruments on dentinal microcrack formation: a micro-computed tomographic study. J Endod 2017; 43: 1166-9.

15. Yared G. Canal preparation using only one $\mathrm{Ni}-\mathrm{Ti}$ rotary instrument: preliminary observations. Int Endod J 2008; 41: 339-44.

16. Berutti E, Chiandussi G, Paolino DS, Scotti N, Cantatore G, Castellucci A, Pasqualini D. Canal shaping with WaveOne Primary reciprocating files and ProTaper system: a comparative study. J Endod 2012, 38: 505-9.

17. Shen Y, Coil JM, Mo AJ Wang Z, Hieawy A, Yang Y, Haapasalo $M$. WaveOne rotary instruments after clinical use. J Endod 2016, 42: 186-9.

18. Gambarini G, Piasecki L, Di Nardo D, Miccoli G, Di Giorgio G, Carneiro E, Al-Sudani D, Testarelli L. Incidence of deformation and fracture of Twisted File Adaptive instruments after repeated clinical use. J Oral Maxillofac Res 2016;7: 1.

19. Pedullà E, Plotino G, Grande N, Avarotti G, Gambarini G, Rapisarda E, Mannocci F. Shaping ability of two nickel-titanium instruments activated by continuous rotation or adaptive motion:a microcomputed tomography study. Clin Oral Invest 2016; 20: 2227-3.

20. Duarte PM, da Silva PB, Alcalde MP, Vivan RR, da Rosa RA, Duarte MAH, Só MVR. Canal transportation, centering ability, and cyclic fatigue promoted by Twisted File Adaptive and Navigator EVO instruments at different motions. J Endod 2018, 44: 1425-9.

21. Karataş E, Gündüz HA, Kırıcı DÖ, Arslan H, Topçu MÇ, Yeter KY. Dentinal crack formation during root canal preparations by the twisted file adaptive, ProTaper Next, ProTaper Universal, and WaveOne instruments. J Endod 2015, 41: 261-4.

22. Helfer AR, Melnick S, Schilder H. Determination of the moisture content of vital and pulpless teeth. Oral Surg Oral Med Oral Pathol Oral Radiol Endod 1972; 34: 661-70.

23. Gher Jr ME, Dunlap RM, Anderson MH, Kuhl LV. Clinical survey of fractured teeth. J Am Dent Assoc 1987; 114: 174-7. 
24. Gutmann JL. The dentin-root complex: anatomic and biologic considerations in restoring endodontically treated teeth. J Prosthet Dent 1992; 67: 458-67.

25. Pilo R, Corcino G, Tamse A. Residual dentin thickness in mandibular premolars prepared with hand and rotatory instruments. J Endod 1998;24: 401-4.

26. Rivera EM, Walton RE. Longitudinal tooth fractures: findings that contribute to complex endodontic diagnoses. Endod Topics 2007; 16: 82-111.

27. Obermayr G, Walton RE, Leary JM, Krell KV. Vertical root fracture and relative deformation during obturation and post cementation. J Prosthet Dent 1991; 66: 181-7.

28. Ertas H, Sagsen B, Arslan H, Er O, Ertas ET. Effects of physical and morphological properties of roots on fracture resistance. Eur J Dent 2014, 8: 261-4.

29. Yamada RS, Armas A, Goldman M, Lin PS. A scanning electron microscopic comparison of a high volume final flush with several irrigating solutions: Part 3. J Endod 1983; 9: 137-42.

30. Ozdemir HO, Buzoglu HD, Çalt S, Çehreli ZC, Varol E, Temel A. Chemical and ultramorphologic effects of ethylenediaminetetraacetic acid and sodium hypochlorite in young and old root canal dentin. J Endod 2012; 38: 204-8.

31. Teixeira C, Felippe M, Felippe W. The effect of application time of EDTA and $\mathrm{NaOCl}$ on intracanal smear layer removal: an SEM analysis. Int Endod J 2005; 38: 285-90.

32. Barutçugil Ç, Arslan H, Yılmaz CB, Yalçın M. Kök kanal tedavisi yapılmış molar dişlerde irrigasyon solüsyonlarının kırılma dirençleri üzerine etkisinin incelenmesi. Atatürk Üniv Diş Hek Fak Derg 2013; 23: 208-13.

33. Schäfer $E$, Zandbiglari $T$, Schäfer J. Influence of resin-based adhesive root canal fillings on the resistance to fracture of endodontically treated roots: an in vitro preliminary study. Oral Surg Oral Med Oral Pathol Oral Radiol Endod 2007;103: 274-9.

34. Karapinar Kazandag M, Sunay H, Tanalp J Bayirli G. Fracture resistance of roots using different canal filling systems. Int Endod J 2009; 42: 705-10.

35. Jainaen A, Palamara J Messer $H$. The effect of resin-based sealers on fracture properties of dentine. Int Endod J 2009; 42: 136-43.

36. Topçuoğlu HS, Arslan H, Keleş A, Köseoğlu M. Fracture resistance of roots filled with three different obturation techniques. Medicina oral, patologia oral y cirugia bucal, 2012;17: e528.
37. Ersoy I, Evcil MS. Evaluation of the effect of different root canal obturation techniques using two root canal sealers on the fracture resistance of endodontically treated roots. Microsc Res Tech 2015; 78: 404-7.

38. Bergmans L, Van Cleynenbreugel J Wevers M, Lambrechts P. Mechanical root canal preparation with NiTi rotary instruments: rationale, performance and safety. Am J Dent 2001;14: 324-33.

39. Tavanafar S, Karimpour A, Karimpour $H$, Saleh AM, Saeed $M H$. Effect of different instrumentation techniques on vertical root fracture resistance of endodontically treated teeth. J Dent 2015; 16: 50.

40. Yusufoglu Sİ, Akman M, Akbulut MB, Eldeniz AÜ. Fracture resistance of roots enlarged with various rotary systems and obturated with different sealers. J Dent Res Dent Clin Dent Prospects 2019; 13: 215.

41. Yoldas O, Yilmaz S, Atakan G, Kuden C, Kasan Z. Dentinal microcrack formation during root canal preparations by different NiTi rotary instruments and the self-adjusting file. J Endod 2012;38:232-5.

42. Capar ID, Saygili G, Ergun H, Gok T, Arslan H, Ertas $\mathrm{H}$. Effects of root canal preparation, various filling techniques and retreatment after filling on vertical root fracture and crack formation. Dent Traumatol 2015;31: 302-7.

43. El Nasr HMA, El Kader KGA. Dentinal damage and fracture resistance of oval roots prepared with single-file systems using different kinematics. J Endod 2014; 40: 849-51.

44. Ashwinkumar V, Krithikadatta J Surendran S, Velmurugan N. Effect of reciprocating file motion on microcrack formation in root canals: an SEM study. Int Endod J 2014; 47: 622-7.

45. Kansal R, Rajput A, Talwar S, Roongta R, Verma $M$. Assessment of dentinal damage during canal preparation using reciprocating and rotary files. J Endod 2014; 40: 1443-6.
Sorumlu Yazarın Yazışma Adresi
Ahmet Demirhan UYGUN
Afyonkarahisar Sağlık Bilimleri Üniversitesi, Diş
Hekimliği Fakültesi, Endodonti A.D.
Afyonkarahisar, 03030, Türkiye
İş telefonu: +90.2722167900
Cep telefonu: +90.505 7513705
Fax numarası: +90.272 2167080
E-mail: ademirhan100@hotmail.com 